\title{
Identification of Face-to-Face Inclusion Complex Formation of Cyclodextrin Bearing an Azobenzene Group by Electrospray Ionization Mass Spectrometry
}

\author{
Ryuichi Arakawa, Takahiro Yamaguchi, and Atsushi Takahashi \\ Department of Applied Chemistry, Kansai University, Osaka, Japan
}

\author{
Tatsuhiko Fujimoto and Takahiro Kaneda \\ The Institute of Scientific and Industrial Research, Osaka University, Osaka, Japan
}

\begin{abstract}
The solution-based self-assembly of native and permethylated cyclodextrins (CD) bearing an azobenzene substituent has been studied by electrospray ionization mass spectrometry (ESI-MS). The results revealed that the CD molecules form either a contact or a face-to-face inclusion complex depending on the interaction of their substituents. The mass spectrometric study further demonstrated that the inclusion complex is formed through the interaction between the host $\mathrm{CD}$ cavity and the guest-substituent and that a contact complex is formed by hydrogen-bonding of the hydroxyl functions at the rims of the CD molecule. We also found that in order to detect the face-to-face inclusion complex by ESI-MS, the following conditions have to be met: (1) The CD moieties must be permethylated to avoid formation of the contact complex, (2) they must possess a guest-substituent of suitable length, such as an azobenzene moiety, and (3) they must possess an $\mathrm{NH}_{2}$ or $\mathrm{OH}$ group at the substituent terminals for protonation and for detection as cations by ESI-MS. Formation of the inclusion complexes was further confirmed by the synthesis of a capped inclusion dimer and a capped monomer. Collision-induced dissociation (CID) experiments have been carried out for the contact, the host-guest inclusion, and the capped inclusion dimers, and the contact complexes are found to be the most stable among them. (J Am Soc Mass Spectrom 2003, 14, 1116-1122) (C) 2003 American Society for Mass Spectrometry
\end{abstract}

$\mathrm{I}$

nterlocked molecules such as rotaxanes and catenanes have been actively studied because of their unique structures and properties [1]. When a guest group is modified with a cyclic host, the molecule may form intramolecular complexes [2] or intermolecular complexes [3] to give supramolecular polymers. When supramolecular polymers are treated with bulky stopper groups, they may form poly[2]rotaxanes [4].

Cyclodextrins (CD) possess a lipophilic cavity that can accommodate organic compounds as guest molecules in polar solvents. Much research on the formation of these host-guest inclusion complexes has been carried out using vapor pressure osmometry, NMR, UVvisible spectrometry, induced circular dichroism spectrometry, and X-ray crystallography. NMR has been commonly used, but sample preparation and spectral assignments are often time-consuming and difficult.

Published online August 28, 2003

Address reprint requests to Dr. R. Arakawa, Department of Applied Chemistry, Kansai University, Suita, Osaka 564-8680, Japan. E-mail: arak@ipcku.kansai-u.ac.jp
NMR measurements can be used to recognize formation of the host-guest inclusion complex, but not to determine the ratios of their host-guest association.

Mass spectrometry (MS) has become an increasingly important tool for examination of non-covalent complexes because it is more sensitive compared with other analytical methods, relatively simple, and most importantly, it provides molecular weight data that allow one to determine stoichiometry. However, MS is particularly difficult to provide structural information of noncovalent complexes. Ashton et al. [5] reported the detection of adduct formation between $\alpha$-CD and Rh metal complexes by fast atom bombardment mass spectrometry (FAB-MS). Electrospray ionization mass spectrometry (ESI-MS) is a relatively soft ionization technique, and it has become one of the most effective methods for direct determination of molecular association of weak non-covalent bonding. Detection of the inclusion complexes between CDs and amino acids or peptides by ESI-MS has been reported [6-8]. However, it was also reported that the detected complexes between $C D$ and amino acids may not be inclusion complexes but rather electrostatic adducts formed dur- 


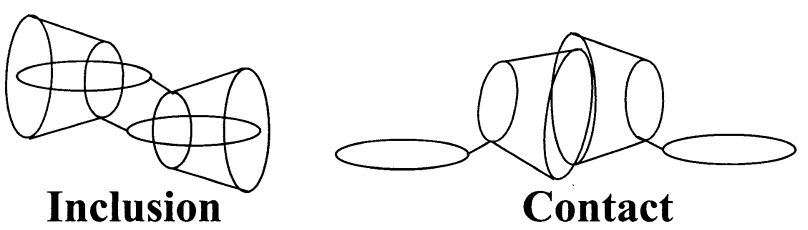

Scheme 1. Two different types of dimmers: (a) a face-to-face inclusion dimer and (b) a hydrogenbonding contact dimer.

ing the electrospray process [7]. Moreover, ESI-MS can be used to study complex formation of CD with 13 different guest benzene derivatives [9] or other guest organic molecules [10], and complex formations between $\beta-\mathrm{CD}$ and several drugs [11-15] were reported. The mass spectrometric study of non-covalent interactions in host-guest chemistry and molecular recognition has been reviewed recently [16].

When a CD modified with an organic guest-substituent forms a face-to-face inclusion complex, a macrocyclic supramolecular complex results. This supramolecular complex is expected to exhibit some new properties and functions different from those of a single CD molecule. Harada and coworkers [17] have chosen cyclodextrin as a cyclic host and 6-hydrocinnamonyl group as a guest moiety to synthesize a supramolecular complex. They determined the formation of a cyclic trimer with a small amount of cyclic dimer and monomer by ${ }^{1} \mathrm{H}$ NMR and MALDI-TOF-MS.

In this study, we have synthesized the native and permethylated $\alpha$-CDs modified with an azobenzene moiety as the guest-substituent. Electrospray ionization time-of-flight mass spectrometry (ESI-TOF-MS) was used to study these $\mathrm{CD}$ derivatives in solution to identify formation of self-assembled supramolecular complexes and to determine the degree of association. To our knowledge, mass spectrometric detection and identification of a self-assembled inclusion complex of CDs with guest-substituents have not been reported.

Depending on the modes of interaction, CD complexes can be formed as contact or as face-to-face inclusion complexes (Scheme 1). The inclusion complex is formed through the hydrophobic interaction between the $C D$ cavity and the $C D$ guest-substituent. On the other hand, the contact complex is formed by hydrogen bonding of a large number of hydroxyl groups at the rims of the $\mathrm{CD}$ skeleton. Our objective is to develop a mass spectrometric analysis to differentiate between the contact and the inclusion complexes and to characterize the formation of an inclusion complex. In order to achieve the objective we have investigated: (1) Complex formation using a permethylated $\mathrm{CD}$ derivative to prevent the formation of contact complexes, (2) synthesis and characterization of the capped inclusion dimers, and (3) collision-induced dissociation (CID) experiments of the contact and inclusion dimers to compare their stabilities.

\section{Experimental}

ESI mass spectra were obtained with a Mariner ESITOF-MS (Applied Biosystems, Tokyo, Japan) in positive ion mode. Samples were prepared as approximately 0.1 $\mathrm{mM}$ solutions in $\mathrm{H}_{2} \mathrm{O} /$ acetonitrile $(1 / 1, \mathrm{vol} / \mathrm{vol})$ and were electrosprayed at a flow rate of $5 \mu \mathrm{L} / \mathrm{min}$. Acetic acid $(0.5 \%)$ was added if it was required to enhance protonation of sample. The spray potential at the needle was $3500 \mathrm{~V}$ higher than the counter electrode. CID experiments were carried out using a triple quadrupole mass spectrometer TSQ700 (Finnigan MAT, Bremen, Germany) with the spray potential set at $4500 \mathrm{~V}$, the acceleration potential varied over $10-180 \mathrm{~V}$, and the flow rate set at $5 \mu \mathrm{L} / \mathrm{min}$.

Chemical structures of the CD derivatives studied are shown in Table 1. The synthesis and NMR studies of CD derivatives 3 [18], 5b [19], 8 [20], 9 [19], and $\mathbf{1 0}$ [20] have been reported. The synthesis of other derivatives 2, 4, 6, 7, $\mathbf{9}_{2}$ will be reported elsewhere. $\alpha-\mathrm{CD}(\mathrm{OMe})_{17}$ denotes that all $\mathrm{OH}$ groups in the $\mathrm{CD}$ derivative are methylated. All azobenzene $\mathrm{CD}$ derivatives are present in trans configurations except for $\mathbf{2}$ and $\mathbf{4}$, which undergo photochemical $\mathrm{N}=\mathrm{N}$ trans-cis isomerization in solution and their cis isomers cannot form a dimer. Therefore, these two samples were wrapped with aluminum foils to shut off light. NMR titration measurements were conducted to examine the formation of the inclusion oligomer complexes in solutions. The results showed that samples 2, 3, 4, 5, 6, and 7 could form inclusion dimers. Formation of a pentamer of $4 b$ was also suggested. The results from NMR titration experiments were included in Table 1.

\section{Results and Discussion}

\section{Differentiation of the Contact and the Inclusion Complexes}

ESI-TOF mass spectra of native $\alpha-\mathrm{CD}(\mathrm{OH})_{18} \mathbf{1 a}$ and permethylated $\alpha-\mathrm{CD}(\mathrm{OMe})_{18} \mathbf{1 b}$ are shown in Figure 1. The mass spectrum of native $C D$ 1a exhibited peaks for both the monomer and the dimer $\left[n \mathrm{M}+\mathrm{Na}^{+}(n=1,2)\right.$ at $m / z 995$ and 1969 , respectively. The ion $[3 \mathrm{M}+2 \mathrm{Na}]^{2+}$ was also observed at $\mathrm{m} / \mathrm{z} 1482$. The permethylated derivative exhibited only a monomeric $[\mathrm{M}+\mathrm{Na}]^{+}$ion at $m / z 1249$, and neither the dimer nor any other oligomer complex was observed. The ion at $\mathrm{m} / \mathrm{z} 1375$ is a $\mathrm{Na}^{+}$adduct ion that resulted from an impurity, 
Table 1. CD derivative structures, mass numbers, MS and NMR results

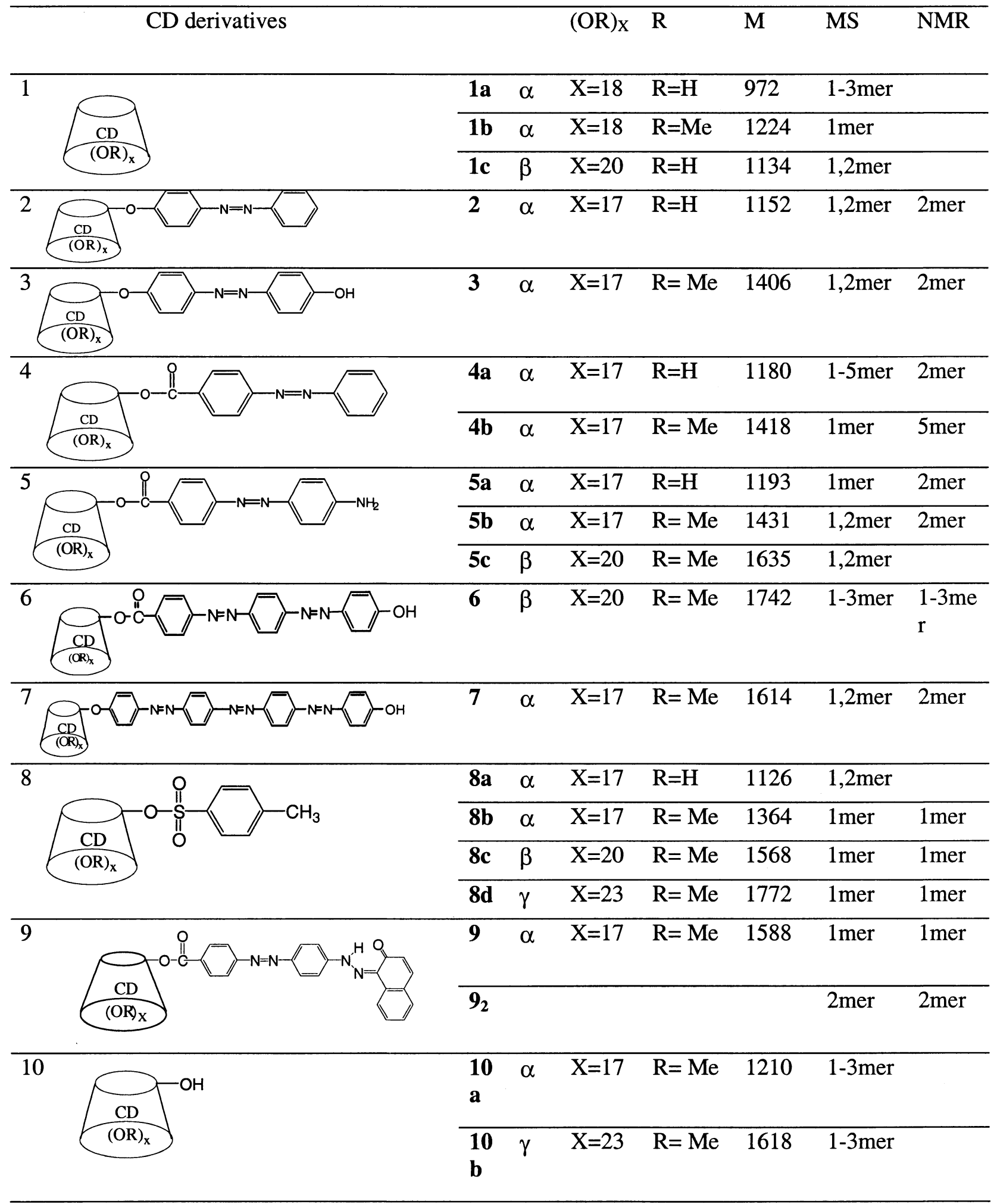

$\alpha$-CD $(\mathrm{OMe})_{16}(\mathrm{OH})_{1}(\mathrm{OTs})_{1}$. The oligomeric ions observed in 1a must be contact complexes formed by hydrogen bonding between the hydroxyl groups because no guest-substituent is present for the formation of an inclusion complex. No oligomer is observed for $\mathbf{1 b}$; the contact complex cannot be formed by hydrogen bonding because all hydroxyl functions are methylated.

The ESI mass spectrum of $\alpha-\mathrm{CD}(\mathrm{OH})_{17} \mathrm{OCOC}_{6} \mathrm{H}_{4-}$ 

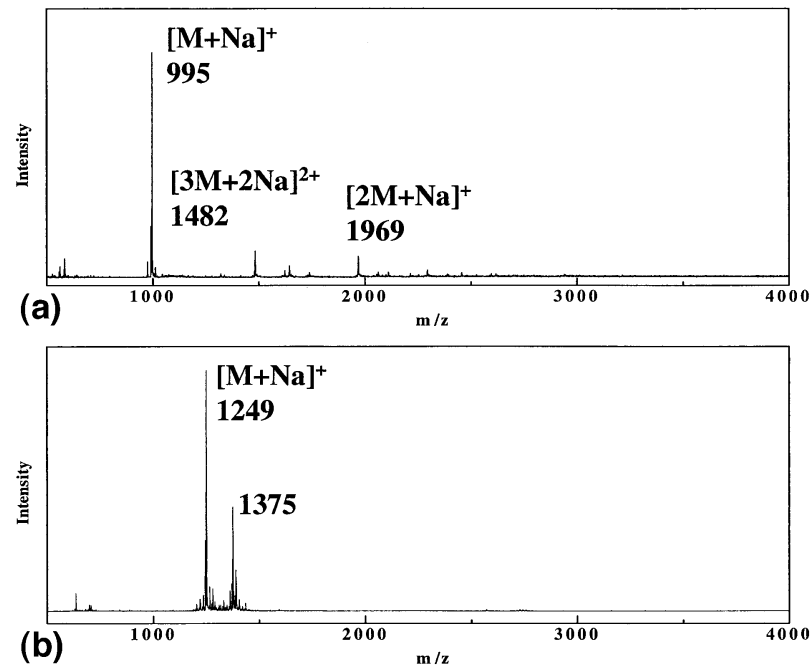

Figure 1. Positive ion ESI-TOF mass spectrum of (a) $\alpha-\mathrm{CD}(\mathrm{OH})_{18}$ $\mathbf{1 a}$, and $(\mathbf{b}) \alpha-\mathrm{CD}(\mathrm{OMe})_{18} \mathbf{1 b}$ in acetonitrile $/ \mathrm{H}_{2} \mathrm{O}(1: 1 \mathrm{vol} / \mathrm{vol})(0.1$ $\mathrm{mM})$.

$\mathrm{NNC}_{6} \mathrm{H}_{5}$ 4a yielded ions at $\mathrm{m} / \mathrm{z} 1204,2385$, and 3566 corresponding to $[n \mathrm{M}+\mathrm{Na}]^{+}(n=1-3)$ (Figure 2). The ions at $\mathrm{m} / \mathrm{z} 1795$ and 2976 in the same mass spectrum are the $2+$ ions $[3 \mathrm{M}+2 \mathrm{Na}]^{2+}$ and $[5 \mathrm{M}+2 \mathrm{Na}]^{2+}$. The oligomeric ions are observed to be more abundant in $\mathbf{4 a}$ than those in 1a. The reason must be that, in addition to the hydrogen bonding contact complexes, the inclusion complexes are also present in $\mathbf{4 a}$.

A dimer complex of $\alpha-\mathrm{CD}(\mathrm{OH})_{17} \mathrm{OC}_{6} \mathrm{H}_{4} \mathrm{NNC}_{6} \mathrm{H}_{5}$ 2, whose presence had been indicated by vapor pressure osmometry and an NMR measurement, was also detected by ESI-MS; however, the peak is less intense than that observed for the dimer of $4 \mathbf{a}$, although the difference is only an additional $\mathrm{CO}$ function in the substituent. This $\mathrm{CO}$ function must somehow contribute to the dimer formation.

The ESI mass spectrum of the permethylated derivative $\alpha-\mathrm{CD}(\mathrm{OMe})_{17} \mathrm{OCOC}_{6} \mathrm{H}_{4} \mathrm{NNC}_{6} \mathrm{H}_{5} \quad 4 \mathbf{b}$ exhibited only a monomeric ion $[\mathrm{M}+\mathrm{Na}]^{+}$, although the NMR experiment had suggested the formation of a pentamer. The failure to detect the inclusion complex may be due to suppression of cationization. The CD cavity in $4 \mathrm{~b}$ is already filled by the guest-substituent and thus there is no extra space to include a $\mathrm{Na}^{+}$ion. At the same time,

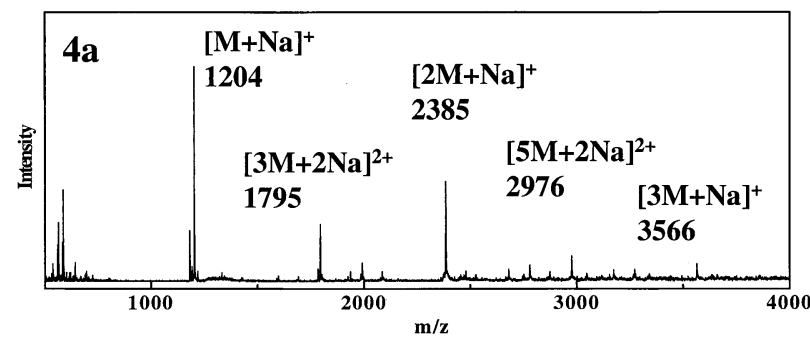

Figure 2. Positive ion ESI mass spectrum of $\alpha-\mathrm{CD}(\mathrm{OH})_{17} \mathrm{OCOC}_{6} \mathrm{H}_{4} \mathrm{NNC}_{6} \mathrm{H}_{5}$ 4a in acetonitrile $/ \mathrm{H}_{2} \mathrm{O}(1: 1 \mathrm{vol} /$ vol) $(0.1 \mathrm{mM})$.
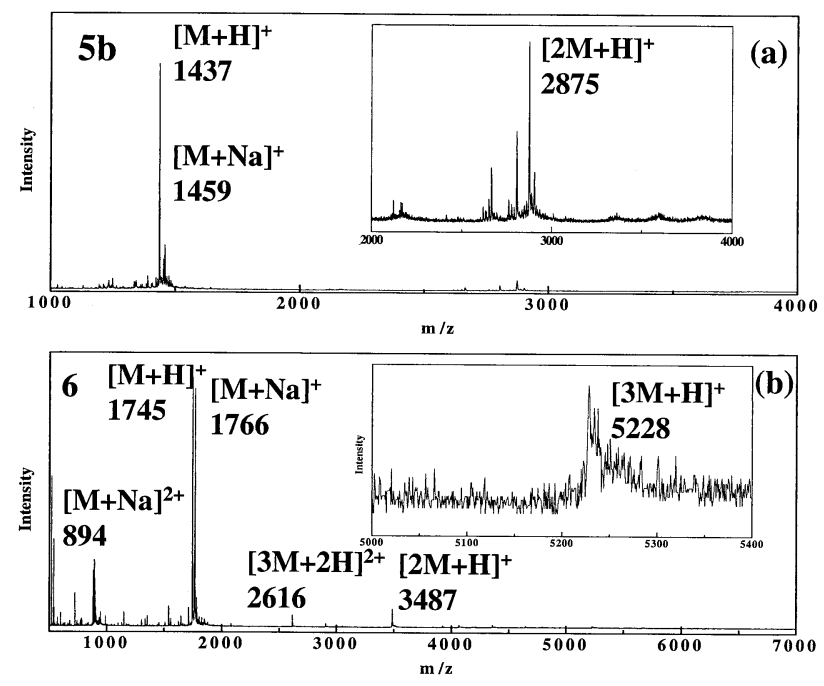

Figure 3. Positive ion ESI mass spectrum of (a) $\alpha$-CD(OMe ${ }_{17} \mathrm{OCOC}_{6} \mathrm{H}_{4} \mathrm{NNC}_{6} \mathrm{H}_{4} \mathrm{NH}_{2} \quad \mathbf{5 b}$ and (b) $\alpha-\mathrm{CD}(\mathrm{OMe})_{17} \mathrm{OCOC}_{6} \mathrm{H}_{4} \mathrm{NNC}_{6} \mathrm{H}_{4} \mathrm{NNC}_{6} \mathrm{H}_{4} \mathrm{OH} 6$ in acetonitrile/ $\mathrm{H}_{2} \mathrm{O}(1: 1 \mathrm{vol} / \mathrm{vol})(0.1 \mathrm{mM})$.

all of the hydroxyl groups in the $\mathrm{CD}$ molecule are methylated so that addition of $\mathrm{Na}^{+}$at those sites should also be suppressed.

In the ESI mass spectrum of $\alpha-\mathrm{CD}(\mathrm{OMe})_{17} \mathrm{OCOC}_{6} \mathrm{H}_{4}-$ $\mathrm{NNC}_{6} \mathrm{H}_{4} \mathrm{NH}_{2} \mathbf{5} \mathbf{b}$ that was obtained upon the addition of acetic acid, the protonated inclusion dimer $[2 \mathrm{M}+\mathrm{H}]^{+}$ was successfully detected at $\mathrm{m} / \mathrm{z} 2875$ (Figure 3). The protonated inclusion dimer was not detected for $\mathbf{4 b}$, even after acetic acid was added. An amino group at the substituent terminal in $\mathbf{5 b}$ enabled the protonation and detection of the dimer ion. Because $\mathbf{5 b}$ is a permethylated $\mathrm{CD}$, the hydrogen bonding contact dimer could not be formed; therefore the dimer of $\mathbf{5 b}$ was formed by face-to-face inclusion. The result was also supported by the NMR measurement. Similarly, the face-to-face inclusion dimer $\left[2 \mathrm{M}+\mathrm{H}^{+}\right.$was also detected with $\beta$ - $\mathrm{CD}(\mathrm{OMe})_{20} \mathrm{OCOC}_{6} \mathrm{H}_{4} \mathrm{NNC}_{6} \mathrm{H}_{4} \mathrm{NH}_{2}$ 5c.

ESI mass spectra of samples $3,5 b, 5 c, 6$, and 7 all exhibited peaks corresponding to $[n \mathrm{M}+\mathrm{H}]^{+}$, and their intensities were enhanced by the addition of acetic acid. The mass spectrum of $\beta-\mathrm{CD}(\mathrm{OMe})_{20} \mathrm{OCOC}_{6} \mathrm{H}_{4} \mathrm{NNC}_{6}$ $\mathrm{H}_{4} \mathrm{NNC}_{6} \mathrm{H}_{4} \mathrm{OH} 6$ is shown in Figure $3 \mathrm{~b}$. In comparing the mass spectra of $\mathbf{6}$ and $\mathbf{5 b}$, it can be seen that the peaks corresponding to oligomeric inclusion complexes are more intense in the spectrum of 6 . A larger cavity in 6 may tend to hold a long guest side chain more tightly to form more stable inclusion complexes. The proton adducts in these $\mathrm{CD}$ complexes must be formed at $-\mathrm{OH}$ or $-\mathrm{NH}_{2}$ of the guest-substituents.

The ESI mass spectra of both $\alpha-\mathrm{CD}(\mathrm{OMe})_{17} \mathrm{OH}$ 10a and $\gamma-\mathrm{CD}(\mathrm{OMe})_{23} \mathrm{OH} \mathbf{1 0 b}$ yielded $[\mathrm{M}+\mathrm{Na}]^{+}$and $[\mathrm{M}+$ $2 \mathrm{Na}]^{2+}$ ions, and in addition, the dimeric $[2 \mathrm{M}+\mathrm{Na}]^{+}$ ions were also detected. The dimeric ion of the $\gamma$-isomer was observed to be more intense than the dimer of the $\alpha$-isomer. The observation suggests that more glucoside rings in the $\gamma$-CD can accomodate a $\mathrm{Na}^{+}$ion more easily 


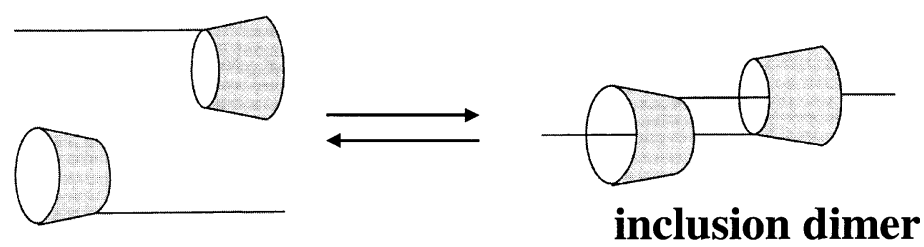

\section{CD in solution}

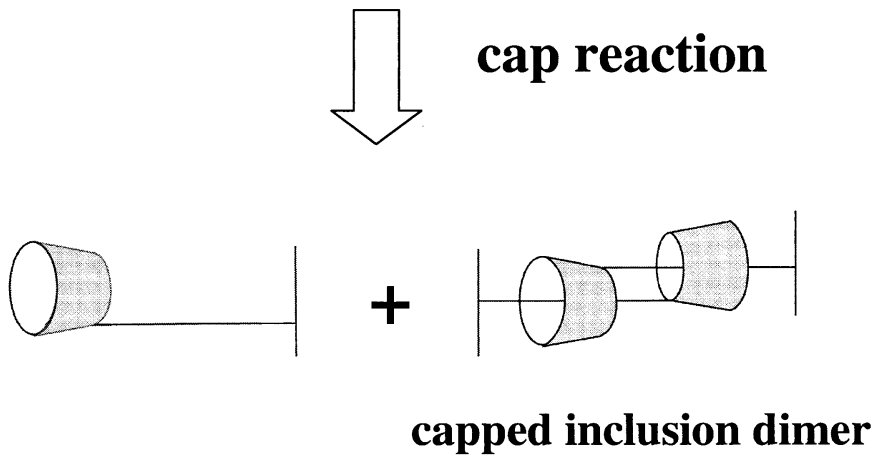

Scheme 2. A schematic representation for the preparation of a capped monomer and a capped inclusion dimer.

into the $\mathrm{CD}$ cavity. These dimeric ions are presumably formed by the hydrogen bonding of the only hydroxyl substituent.

\section{Influence of the Length of the Guest-Substituents}

In order to examine the influence of the length of the substituents, a $\mathrm{CD}$ derivative with a $p$-toluenesulfonyl substituent $\alpha-\mathrm{CD}(\mathrm{OH})_{17} \mathrm{OSO}_{2} \mathrm{C}_{6} \mathrm{H}_{4} \mathrm{CH}_{3}$ 8a was used. Its spectrum exhibited a weak dimeric ion; however, the mass spectrum of the permethylated derivative $\alpha$ - $\mathrm{CD}(\mathrm{OMe}){ }_{17} \mathrm{OSO}_{2} \mathrm{C}_{6} \mathrm{H}_{4} \mathrm{CH}_{3}$ contained no dimeric ion, but only $[\mathrm{M}+\mathrm{Na}]^{+}$and $[\mathrm{M}+2 \mathrm{Na}]^{2+}$ ions. No dimeric ions were detected for two other permethylated derivatives, $\beta-\mathrm{CD}(\mathrm{OMe})_{20} \mathrm{OSO}_{2} \mathrm{C}_{6} \mathrm{H}_{4} \mathrm{CH}_{3} 8$ cand $\gamma-\mathrm{CD}(\mathrm{OMe})_{23^{-}}$ $\mathrm{OSO}_{2} \mathrm{C}_{6} \mathrm{H}_{4} \mathrm{CH}_{3} 8 \mathrm{~d}$. The presence of oligomeric complexes in these tosyl derivatives was not indicated by NMR measurements either. The dimeric ion detected for 8a is likely a contact dimer and not an inclusion dimer. The inclusion complex may not be detected because the tosyl substituents in these derivatives are too short to be held in the $\mathrm{CD}$ cavities to form a stable inclusion complex.

From the above observation, the requirements for detecting an inclusion complex by ESI-MS can be summarized as following: (1) The CD molecules have to be permethylated in order to avoid formation of a contact complex, (2) the guest-substituent must be of a suitable length, such as an azobebzene moiety, in order to enable interaction between the substituent and the CD cavity, and (3) the guest-substituents must possess a terminal functional group such as $\mathrm{OH}$ or $\mathrm{NH}_{2}$ for cationization.

\section{Formation of the Capped Dimers}

Because the monomer and the inclusion dimer of $\alpha \mathrm{CD}(\mathrm{OMe})_{17} \mathrm{OCOC}_{6} \mathrm{H}_{4} \mathrm{NNC}_{6} \mathrm{H}_{4} \mathrm{NH}_{2} \mathbf{5 b}$ were present in the solution as an equilibrium mixture, we reacted this solution with 2-naphthol (Scheme 2) in order to cap the guest-substituents in both the monomer and the dimer by diazocoupling reaction. The products, the capped monomer

$\alpha-\mathrm{CD}(\mathrm{OMe})_{17} \mathrm{OCOC}_{6} \mathrm{H}_{4} \mathrm{NNC}_{6} \mathrm{H}_{4} \mathrm{NHNC}_{10} \mathrm{H}_{7} \mathrm{O} 9$ and its capped dimer $\mathbf{9}_{2}$, were separated by column chromatography. The ESI mass spectrum of the capped monomer 9 (Figure 4a) exhibited no dimer. Since the monomer has been capped, its guest-substituent is unable to enter the CD cavity to form a dimer. However, it is more important to find that no dimer at all was formed with 9, although the molecule still contains a terminal $\mathrm{NH}$ or $\mathrm{OH}$ function (equilibrium in solution) at the guest-substituent. It therefore suggests that those oligomeric complexes that we have detected in the spectra of the $C D$ derivative $3,5,6,7$ are not contact complexes that result from hydrogen bonding at their terminal functions; the detected dimers are inclusion complexes.

The mass spectrum of the capped dimer $\mathbf{9}_{\mathbf{2}}$ (Figure 4b) exhibited the expected ion $\left[\mathbf{9}_{\mathbf{2}}+\mathrm{Na}\right]^{+}$at $\mathrm{m} / z 3201$. The peak at $m / z 1612$ is the impurity $[9+\mathrm{Na}]^{+}$.

\section{Stability of the Dimers by CID Experiments}

CID experiments were carried out with a TSQ700 mass spectrometer using argon as the collision gas to examine the stabilities of the contact complex of $\mathbf{1 a}$, the inclusion complexes of $\mathbf{5 b}$ and $\mathbf{5 c}$, and the capped dimer 

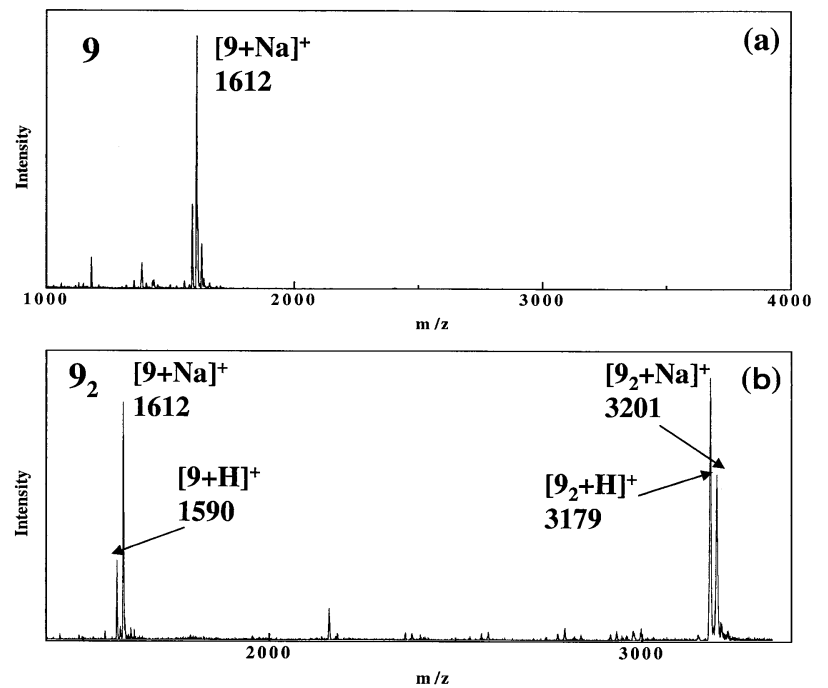

Figure 4. Positive ion ESI mass spectrum of (a) the capped monomer of $\alpha-\mathrm{CD}(\mathrm{OMe})_{17}-\mathrm{OCO} \mathrm{C}_{6} \mathrm{H}_{4} \mathrm{NNC}_{6} \mathrm{H}_{4} \mathrm{NHNC}_{10} \mathrm{H}_{7} \mathrm{O}, 9$ and (b) the capped inclusion dimer, $\mathbf{9}_{\mathbf{2}}$ in acetonitrile $/ \mathrm{H}_{2} \mathrm{O}(1: 1$ $\mathrm{vol} / \mathrm{vol})(0.1 \mathrm{mM})$.

of $\mathbf{9}_{2}$. The CID mass spectrum of the contact dimer $\alpha-\mathrm{CD}(\mathrm{OH})_{18}$ 1a $[2 \mathrm{M}+\mathrm{H}]^{+}$yielded multiple peaks separated by intervals of $162 \mathrm{Da}$, the mass of the glucoside units (Figure 5). The change in the ratio of the intensity of the monomer fragment $[\mathrm{M}+\mathrm{H}]^{+}$to the parent dimer $[2 \mathrm{M}+\mathrm{H}]^{+}$was measured as a function of $\mathrm{CID}$ acceleration voltage. Figure 6 shows an example of the changes obtained with the dimer $[2 \mathrm{M}+\mathrm{H}]^{+}$of $\alpha$-CD(OMe ${ }_{17} \mathrm{OCOC}_{6} \mathrm{H}_{4} \mathrm{NNC}_{6} \mathrm{H}_{4} \mathrm{NH}_{2}(5 \mathbf{b})_{2}$. The acceleration voltage $\mathrm{V}_{0}$ at which the intensity of the monomer and dimer are equal was measured, and the center-of-mass energy $\mathrm{E}_{\mathrm{CM}}=\mathrm{m}_{\mathrm{T}} \mathrm{E}_{\mathrm{LAB}} /\left(\mathrm{m}_{\mathrm{P}}+\mathrm{m}_{\mathrm{T}}\right)$ was calculated. The laboratory collision energy $\mathrm{E}_{\mathrm{LAB}}$ was maintained equal to the acceleration voltage. $m_{P}$ is the mass of transmitted parent ions and $\mathrm{m}_{\mathrm{T}}$ is the molecular weight of a target gas. This formula represents effective maximum energy derived from the internal excitation of the transmitted ion after collision. The results are summarized in Table 2. The analysis of the CID data indicated that the order of stability of the dimers is as follows: $(\mathbf{1 a})_{2}>(\mathbf{5 c})_{\mathbf{2}}>\mathbf{9}_{\mathbf{2}}>(\mathbf{5 b})_{2}$. The contact complex is apparently more stable than the inclusion complexes,

CID: $\alpha-\mathrm{CD} 40 \mathrm{~V}$

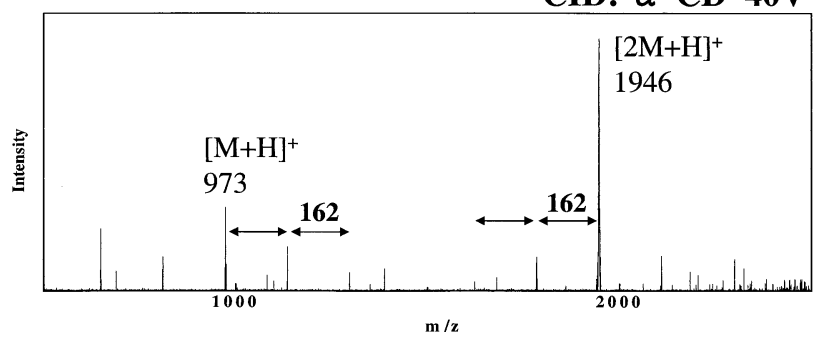

Figure 5. Collision-induced dissociation (CID) spectrum of the contact dimer $[2 \mathrm{M}+\mathrm{H}]^{+}$ion of $\alpha-\mathrm{CD}(\mathrm{OH})_{18}$ at the collision energy $40 \mathrm{eV}$.

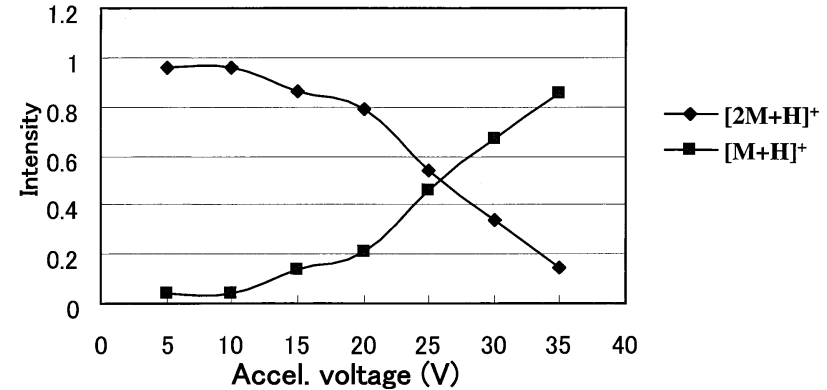

Figure 6. Ion intensities versus acceleration voltage in the CID experiment for the inclusion dimer ion $[2 \mathrm{M}+\mathrm{H}]^{+}$of $\alpha-\mathrm{CD}(\mathrm{OMe})_{17} \mathrm{OCOC}_{6} \mathrm{H}_{4} \mathrm{NNC}_{6} \mathrm{H}_{4} \mathrm{NH}_{2} 5 \mathbf{b}$.

and the dimer with a larger $\mathrm{CD}$, the $\beta$-isomer $(5 \mathrm{c})_{2}$, is more stable than the $\alpha$-isomer $(5 \mathbf{b})_{2}$. The CID experiments of the monomer have also revealed that the monomeric $\beta$-isomer $\mathbf{5 c}$ is more stable than the $\alpha$-isomer $\mathbf{5 b}$. The CID experiment indicated that the capped dimer $\mathbf{9}_{\mathbf{2}}$ was not very stable, which is probably not due to dissociation at the capped moiety, but rather attributable to the preferential breakage of the weak acetal linkage at the $\mathrm{CD}$.

\section{Conclusion}

The structural recognition between the hydrogen bonding contact complex and the host-guest inclusion complex of CD derivatives has been explored by ESI-MS. The inclusion complexes, but not the hydrogen bonding contact complexes, were detected with the permethylated $\mathrm{CD}$ derivatives. However, permethylation suppresses the proton or $\mathrm{Na}^{+}$affinity of these complexes, so that detection using ESI-MS becomes difficult. The required characteristics that a $C D$ must have in order to be detected as an inclusion complex are: (1) It must be permethylated, (2) the guest-substituent must be of sufficient length, such as an azobenzene moiety, and (3) the guest-substituents must bear a cationphilic terminal group, such as $\mathrm{NH}_{2}$ or $\mathrm{OH}$. $\mathrm{CD}$ derivatives with a short tosyl substituent cannot form an inclusion complex. This substituent cannot function as a guest. The formation of the inclusion complexes is further confirmed by the synthesis and the ESI-MS measurements of the capped monomer and the capped dimers. CID experiments have been conducted on the contact, the inclusion, and the capped inclusion dimers. The stabilities of

Table 2. CID acceleration potentials of the protonated dimers and the center-of-mass energies

\begin{tabular}{lcc}
\hline $\begin{array}{l}\text { Precursor } \\
\text { dimer ion }\end{array}$ & $\begin{array}{c}\text { Acceleration voltage, } \\
\mathrm{V}_{\mathrm{o}} / \text { volt }\end{array}$ & $\begin{array}{c}\text { Center-of-mass energy, } \\
\mathrm{E}_{\mathrm{CM}} / \mathrm{eV}\end{array}$ \\
\hline \hline$\left[(\mathbf{1 a})_{2}+\mathrm{H}\right]^{+}$ & 50 & 1.01 \\
{$\left[(\mathbf{5 a})_{2}+\mathrm{H}\right]^{+}$} & 25 & 0.34 \\
{$\left[(\mathbf{5 b})_{2}+\mathrm{H}\right]^{+}$} & 50 & 0.60 \\
{$\left[\mathbf{9}_{2}+\mathrm{H}\right]^{+}$} & 30 & 0.37 \\
\hline
\end{tabular}


these dimers have been compared, and the contact dimers are found to be the most stable.

\section{Acknowledgments}

This work was supported by CREST of Japan Science and Technology (JST) and by a Grant-in-Aid for Scientific Research from the Ministry of Education, Science, Sports, and Culture, Japan.

\section{References}

1. Amabilino, D. B.; Stoddart, J. F.; Chem. Rev., 1995, 95, 2725; (b) Harada, A.; Adv. Plym. Sci., 1997, 133, 141.

2. Hamasaki, K.; Ikeda, H.; Nakamura, A.; Ueno, A.; Toda, F.; Suzuki, I.; Osa, T. J. Am. Chem. Soc. 1993, 115, 5035.

3. Zanotti-Gerosa, A.; Solari, E.; Giannini, L.; Chiesi-Villa, A.; Rizzoli, C. Chem. Commun. 1996, 119.

4. Ashton, P. R.; Baxter, I.; Cantrill, S.; Fyfe, M. C. T.; Glink, P. T.; Stoddart, J. F.; White, A. J. P.; Williams, D. J. Angew. Chem. Int. Ed. 1998, 37, 1294.

5. Ashton, P. R.; Stoddart, J. F.; Zarzycki, R. Tetrahedron Lett. 1988, 29, 2103-2106.

6. Camilleri, P.; Hanskins, N. J.; New, A. P.; Saunders, M. R. Rapid Commun. Mass Spectrom. 1993, 7, 949-952.
7. Cunniff, J. B.; Vouros, P. J. Am. Soc. Mass Spectrom. 1995, 6 437-447.

8. Sun, W.; Cui, M.; Liu, S.; Song, F.; Eikin, Y. N. Rapid Commun. Mass Spectrom. 1998, 12, 2016-2022.

9. Lamcharfi, E.; Chuilon, S.; Kunesch, G.; Libot, F.; Virelizer, H. J. Mass Spectrom. 1996, 31, 982-986.

10. Shahgholi, M.; Copper, C. L.; Callahan, J. Supramol. Chem. 1998, 9, 263-276.

11. Sun, W.; Liu, J.; Cui, M.; Song, F.; Liu, S. Rapid Commun. Mass Spectrom. 1999, 13, 950-953.

12. Miyake, K.; Hirayama, F.; Uekama, K. J. Pharmacol. Sci. 1999, $88,39-45$.

13. Bakhtiar, R. Eur. Mass Spectrom. 1999, 5, 1-5.

14. Kobetic, R.; Jursic, B. S.; Bonnette, S.; Tsai, J. S. C. Salvatore S. J. Tetrahedron Lett. 2001, 42, 6077-6082.

15. Bongiorno, D.; Ceraulo, L.; Mele, A.; Panzeri, W.; Selva, A.; Liveri, V. T. J. Mass Spectrom. 2001, 36, 1189-1194.

16. Schalley, C. A. Int. J. Mass Spectrom. 2000, 194, 11-39.

17. Hoshino, T.; Miyauchi, M.; Kawaguchi, Y.; Yamaguchi, H.; Harada, A. J. Am. Chem. Soc. 2000, 122, 9876-9877.

18. Fujimoto, T.; Nakamura, A.; Inoue, Y.; Sakata, Y.; Kaneda, T. Tetrahedron Lett. 2001, 42, 7987-7989.

19. Kaneda, T.; Yamada, T.; Fujimoto, T.; Sakata, Y. Chem. Lett. 2001, 1264-1265.

20. Kaneda, T.; Fujimoto, T.; Goto, J.; Asano, K.; Yasufuku, Y.; Jung, J. H.; Hosono, C.; Sakata, Y. Chem. Lett. 2002, 514-515. 